\title{
La construcción del «fracaso escolar» en España. Génesis y cristalización de un problema social
}

\author{
Javier Rujas Martínez-Novillo \\ Universidad Complutense de Madrid \\ javier.rujas@ucm.es
}

Recepción: 25-02-2016

Aceptación: 29-09-2016

\section{Resumen}

Este artículo analiza la génesis del «fracaso escolar» como problema social y público en España. Parte de un estudio sociohistórico basado en diversos documentos (prensa, revistas educativas, legislación, informes oficiales y libros). Pese a la evidencia con la que se nos presenta hoy en día, el «fracaso escolar» es un problema relativamente reciente: aunque pueden localizarse algunos antecedentes a finales del siglo xIX y principios del xx, no emerge como problema social hasta los años sesenta y setenta, cristalizando definitivamente como problema público en 1980. Este proceso es el resultado de un trabajo colectivo de enunciación que movilizó a actores diversos en un contexto de extensión de la escolarización y el credencialismo, de transformación de la forma escolar, de emergencia de las nuevas clases medias, de formación de un campo de expertos de la infancia y la adolescencia, de desarrollo de las ciencias sociales y de la educación y de redefinición del espacio público y el campo político.

Palabras clave: fracaso escolar; problema social; problema público; sociología histórica; sociología de la educación 
Abstract. The Construction of "School Failure" in Spain: Genesis and Crystallization of a Social Problem

This paper analyses the emergence of "school failure" as a social and public problem in Spain, drawing on a socio-historical study based on a variety of documents (press, educational reviews, legal texts, official reports and books). Although apparently self-evident, "school failure" (understood in Spain as not graduating from compulsory secondary education) is a fairly recent problem: while some precedents might be found in the late nineteenth century and early twentieth, it emerged as a social problem in the 1960 s and finally crystallized as a public problem in 1980. This process is the result of a collective work of enunciation that mobilized different actors in a context of expanded schooling, spreading credentialism, changes in school organization, emergence of the new middle classes and a field of experts on childhood and youth, the development of social and educational sciences, and the reshaping of public space and the political field.

Keywords: school failure; social problems; public problems; historical sociology; sociology of education

\section{Sumario}

1. Introducción 4. Génesis del problema: del auge de las

2. Condiciones de aparición

3. Antecedentes: la invención del «rendimiento» y del «retraso» escolares «inadaptaciones» al modo de educación tecnocrático

5. Conclusiones

Referencias bibliográficas

Anexo. Cronología (1950-1982)

\section{Introducción ${ }^{1}$}

El problema del «fracaso escolar» está de actualidad en los últimos tiempos. Sucesivos ministros de Educación lo han definido como el problema más importante de la educación en España y rara es la noticia sobre educación que no lo mencione. Objeto de múltiples discursos, aparece naturalmente como un problema público de primer orden que reclama solución y exige políticas y dispositivos específicos.

Sin embargo, el carácter evidente y natural de los fenómenos sociales hace que olvidemos con frecuencia su génesis, así como los procesos que los instituyen como tales. Pese a la evidencia con la que se nos presenta hoy en día, el «fracaso escolar» no siempre fue considerado un problema por la sociedad española. Situado en el tiempo largo, aparece como un problema de constitución reciente, ligado a una serie de transformaciones sociales más amplias y a todo

1. Este trabajo forma parte de una tesis doctoral realizada gracias al programa de Formación del Profesorado Universitario (FPU) del MEC y se enriqueció con los comentarios de mis directores, Araceli Serrano y Rafael Feito, así como de los miembros del tribunal de tesis. Parte del mismo se presentó en las II Jornadas de Investigación Social de la Facultad de Ciencias Políticas y Sociología de la UCM y en la XVI Conferencia de Sociología de la Educación. 
un trabajo colectivo de enunciación, movilización de actores y elaboración de la categoría que ha acabado por imponerla como principio de visión y división del mundo social.

El «fracaso escolar» es el producto de un proceso histórico de problematización que tiene lugar en sociedades europeas - con características diferentesen la segunda mitad del siglo $\mathrm{xx}$, con algunos antecedentes a finales del siglo XIX y principios del $\mathrm{xx}$ y diversas ramificaciones y reconfiguraciones hasta nuestros días. Además, el «fracaso escolar» es, en buena medida, un significante vacio que adopta sentidos y connotaciones distintas según los contextos históricos y los grupos sociales. Es objeto de luchas que trascienden el ámbito escolar y que involucran a una diversidad de especialistas de otros campos en la definición y en la intervención del problema, así como en la pugna más o menos explícita por imponer la visión legítima del mismo, de sus causas y sus soluciones.

Este artículo presenta un análisis sociohistórico de la génesis del «fracaso escolar» como problema social y público en España, que concluye con su cristalización definitiva a principios de los ochenta. Para ello, se basa en el análisis de documentos producidos entre finales del siglo XIX y esa fecha (prensa, revistas educativas, legislación, informes oficiales y libros), así como en otros trabajos históricos y sociológicos ${ }^{2}$. Pueden distinguirse dos fases en la génesis del problema. Una primera, a finales del siglo XIX y principios del Xx, en la que pueden identificarse algunos antecedentes del «fracaso escolar». Una segunda, entre 1960 y 1980 , en la que emerge y cristaliza progresivamente como problema social y público. Antes de entrar en el detalle de ambas fases, nos detendremos brevemente en las condiciones de aparición del problema.

\section{Condiciones de aparición}

El surgimiento de un problema social es, por lo general, el resultado de la conjunción de una serie de transformaciones objetivas, de un trabajo colectivo de enunciación, movilización, elaboración de categorías e identidades, que logran (o no) imponer el reconocimiento y la legitimación del problema como tal, y de un proceso de institucionalización que tiende a fijar las categorías, a designar agentes competentes para resolverlo y a establecer programas de acción y modos de gestión del mismo (Lenoir, 1990). En el caso del «fracaso escolar», en el sentido dominante que tiene en la actualidad (el hecho de no completar

2. Esta línea de investigación ha sido desarrollada por Isambert-Jamati (1992), Ravon (2000) o Morel (2010) para el caso francés (échec scolaire) y por Dorn (1996) para Estados Unidos (dropout). En la sociología de la educación española, sin embargo, existe un relativo vacío en cuanto al análisis de la construcción histórica del problema, aunque se haya esbozado (Carabaña, 2003: 18-32; Fernández Enguita et al., 2010: 19). La perspectiva de análisis (basada en la genealogía y en la sociología de los problemas públicos) y la metodología (construcción del corpus y análisis sociológico del discurso) se detallan más ampliamente en Rujas (2015: 45-54), así como el análisis del periodo que va de 1980 a la actualidad (Rujas, 2015: 139-162). 
Tabla 1. Reformas de la educación obligatoria en España

\begin{tabular}{lcc}
\hline Normas & n. ${ }^{\circ}$ de años & edades \\
\hline Ley Moyano (1857) & 3 & 6 a 9 \\
Decreto Romanones (1901) & 6 & 6 a 12 \\
Estatuto del Magisterio (1923) & 8 & 6 a 14 \\
Ley de educación primaria (1945) & 6 & 6 a 12 \\
Ley de ampliación (1964) & 8 & 6 a 14 \\
LOGSE (1990) & 10 & 6 a 16 \\
\hline
\end{tabular}

Fuente: Cuesta (2005)

la escolaridad obligatoria), pueden señalarse varias condiciones de aparición del problema, que fueron engarzándose pieza a pieza de forma no lineal ${ }^{3}$.

Una de estas condiciones es el proceso de escolarización. La imposición de la escolaridad obligatoria por parte del Estado se logró con muchas dificultades y resistencias desde sus inicios, y se fue conquistando lentamente contra el trabajo infantil y los modos de educación no escolares (Varela y Álvarez-Uría, 1991). Sus sucesivas declaraciones y ampliaciones legales (tabla 1) tardaron mucho en hacerse efectivas: no se alcanzó la escolarización completa de la población de 6 a 12 años hasta mediados de la década de 1970 (tabla 2), cuando se consolidó finalmente «la escuela como un espacio de socialización obligatorio frente al hogar, el lugar de trabajo o la calle» (Viñao, 2004: 232). Asimismo, desde la década de 1950 y sobre todo de 1960, el bachillerato conocería un fuerte aumento de matriculados (Lerena, 1976: 207; Fernández Enguita, 1994: 122123; Carabaña, 1999: 722-723), abriéndose progresivamente a franjas más amplias de población. No obstante, estos cambios en la demografía escolar no explican por sí solos la emergencia del problema.

Importan también los cambios en la configuración institucional de la escuela. En el primer tercio del siglo xx, se comenzó a introducir un nuevo modelo institucional en la enseñanza primaria, adaptado de la enseñanza secundaria, que acabaría sustituyendo al entonces predominante de la escuela unitaria - una sola aula, un solo maestro, alumnos de edades y conocimientos dispares- y convirtiéndose en el modelo normal de escuela primaria en los años setenta: la escuela graduada, "con varias aulas, maestros, grados y alumnos clasificados y agrupados, lo más homogéneamente posible, en función de su edad y conocimientos» (Viñao, 1990: 8). Con ello se introducirían cambios fundamentales en la organización escolar (Perrenoud, 1990: 78-79; Viñao, 1990: 8): sustitución

3. Una diversidad de significados se asocian a la noción de fracaso escolar, sin que por ello índice de la institucionalización del problema - se vea alterada la percepción de que se está hablando de una misma cosa, ni la percepción de su carácter problemático. Se confunde con dificultad escolar y dificultades de aprendizaje, y se usa habitualmente como sinónimo de malas notas, suspensos en pruebas o exámenes, repetición de curso, frustración psicológica, bajo rendimiento escolar o no compleción de los objetivos pedagógicos asignados a un curso, ciclo $o$ edad. No obstante, en España predomina su asociación a la «no titulación en ESO a la edad teórica» (definición arbitraria y credencialista). 
Tabla 2. Tasas de escolarización en la enseñanza básica (1830-1975)

\begin{tabular}{cccc}
\hline Año & 6 a 12 años & 6 a 13 años & 6 a 14 años \\
\hline 1830 & 24,7 & & \\
1860 & 44,9 & & \\
1908 & 47,3 & & \\
1923 & 50,7 & & \\
1931 & 51,8 & & \\
1934 & 56,5 & & \\
1950 & 71 & & \\
1952 & $69,1(6$ a 11) & 76 & \\
1955 & 76 & 84 & - \\
1963 & - & 93,3 & 100 \\
1966 & 87,6 & 100 & \\
1971 & 94,4 & & \\
1975 & 100 & & \\
\hline
\end{tabular}

Fuente: elaboración propia a partir de Cuesta (2005) para 1830-1955 y Fundación Foessa (1970, 1983) para 1966-1975.

del método individual por el mutuo, simultáneo o mixto; agrupación de los alumnos en cursos en función de un nivel similar de conocimientos, con maestros y espacios específicos; establecimiento de un currículo unificado, secuencial y progresivo, y establecimiento de exámenes de paso entre cursos. A esto se añadirá la configuración, en los años setenta, de una enseñanza básica con tronco común de los 6 a los 14 años, rompiendo con el sistema dual hasta entonces vigente, en el que la escuela primaria pública era frecuentada fundamentalmente por las clases populares y las enseñanzas secundaria —que comenzaba a los 10 años- y universitaria estaban orientadas a las clases medias y altas.

Además, no hay éxito o fracaso sin un determinado sistema de evaluación y examen (Perrenoud, 1990) que, en base a un currículo y a unas normas del juicio escolar, establezca los límites entre uno y otro, que sirva a la escuela para aprobar, suspender, hacer repetir y definir como «atrasados» o «avanzados». Sin embargo, esa no es condición suficiente para que fallar una determinada prueba se considere o se experimente como un fracaso. Durante mucho tiempo, los exámenes en la universidad y en la enseñanza secundaria fueron meros rituales, y los fracasos, excepcionales, debido a la fuerte selección previa y al asesoramiento de los docentes, que recomendaban no presentarse a quien no consideraban preparado (Sánchez Sarto, 1936: 1286). Del mismo modo, en la enseñanza primaria, a principios del siglo xx, los exámenes públicos y orales de los alumnos ante las autoridades locales y los padres fueron sustituidos por la exposición de trabajos escolares, que persistieron hasta el establecimiento de los exámenes de promoción en los años sesenta (Orden de 22 de abril de 1963; Viñao, 2004: 137). Esos "fracasos escolares» particulares en pruebas concretas, una de las bases de la problematización del «fracaso escolar», son también, por tanto, una realidad histórica relativamente reciente. 
Asimismo, en la génesis del problema intervienen transformaciones más amplias de la estructura social y económica española. En las décadas de 1960 y 1970, la industrialización, la desruralización y el inicio de terciarización y asalarización (Tezanos, 2001) dan lugar a la emergencia de las llamadas nuevas clases medias, entre las que se reclutará una buena parte de los expertos en la infancia y en las dificultades escolares. Progresivamente, además, aumentan los requisitos de cualificación de los puestos de trabajo y la centralidad del capital escolar en la estratificación social.

Se puede señalar una última condición en la que no se repara con tanta frecuencia: la constitución de un campo de la infancia inadaptada (Pinell y Zafiropoulos, 1983) formado por distintos expertos de la infancia y la adolescencia desde finales del siglo XIx. Progresivamente, se va a diferenciar a los niños considerados de inteligencia normal de los «deficientes» o «subnormales», para los que se constituirán una pedagogía, un cuerpo docente e instituciones específicas. Ello favorecerá la emergencia del «fracaso escolar», noción ligada al interés creciente, en la segunda mitad del siglo XX, por los niños «bien dotados» que "fracasan».

Como veremos, sin todos estos cambios, sería impensable lo que hoy llamamos «fracaso escolar».

\section{Antecedentes: la invención del «rendimiento»y del «retraso» escolares}

Si bien el término fracaso escolar no se generaliza en España hasta entrados los años setenta, no se trata de una preocupación social completamente nueva que emerja de la nada. Frente al nominalismo ingenuo que ve en la aparición de la etiqueta el nacimiento del problema, conviene resituar su formulación, no solo en las transformaciones sociales que posibilitan su aparición, sino también en el espacio de las producciones expertas y las preocupaciones sociales y políticas que se desarrollan desde principios de siglo alrededor de la infancia y la juventud, sus problemas y su educación.

Entre finales del siglo xIx y principios del xx, la centralización y la consolidación de un sistema educativo estatal en España encuentra apoyo en los discursos que afirman la necesidad de realizar una regeneración pedagógica para la regeneración nacional (Puelles, 2000). Se consolida entonces la idea de la necesidad de educar al pueblo no solo transmitiéndole unos conocimientos básicos - leer, escribir, contar—, sino también civilizándole y moralizándole - higiene, moral cristiana-, así como protegiendo a los niños de las «perversiones» que reinan en la calle y en los entornos miserables (Varela y AlvarezUría, 1991). Fijada una cierta noción de infancia en el siglo XIx (Ariès, 1972; 1986), se desarrollan a su alrededor toda una serie de movimientos, instituciones y saberes especializados (movimiento de asistencia y protección a la infancia, justicia de menores, paidología, psicología y pedagogía científicas, psiquiatría, pediatría, puericultura): un mercado de la infancia (Muel-Dreyfus, 1983: 219). Además, a principios del siglo xx, con la imposición de la escolaridad obligatoria, la escuela primaria comienza a acoger cada vez más a las 
clases populares y surgen a su alrededor nuevas preocupaciones, estudios y categorías (Muel, 1975; Pinell y Zafiropoulos, 1983; Varela y Álvarez-Uría, 1991) que van a constituir un antecedente importante en la problematización del «fracaso escolar».

En España, entre 1830 y 1908, la proporción de alumnos escolarizados en la educación básica pasa del 25\% al 50\% de los niños entre 6 y 12 años, y se mantiene más o menos estable hasta la guerra (tabla 2, más arriba). Si no empieza a aplicarse la dicotomía éxito-fracaso al rendimiento escolar de los alumnos al menos hasta las décadas de 1920 y 1930, en los estudios que se desarrollan entonces sobre la infancia anormal y la inteligencia emergen nuevas categorías que se asociarán a la de «fracaso escolar» en el último tercio de siglo: la psicología y la pedagogía científicas se preguntan por el rendimiento de la acción pedagógica y buscan las causas en el propio niño, desarrollando conceptos y métodos de medida del desarrollo intelectual. La pedagogía, en proceso de institucionalización desde finales del siglo XIX, busca en los saberes científicos, especialmente en una psicología también en crecimiento, un apoyo que servirá para legitimar científicamente las nuevas doctrinas pedagógicas.

Aunque desde el siglo XviII se desarrollan clasificaciones de las enfermedades mentales infantiles, no es hasta la imposición de la escuela obligatoria cuando estas empiezan a tomar el aprendizaje escolar como medida de la normalidad infantil (Huertas, 1998). Se distinguen entonces nuevas categorías de infancia: la infancia peligrosa o delincuente, que no cumple la obligatoriedad escolar y pasa el tiempo en la calle, y la infancia anormal, que asiste a las clases pero no se acomoda a las normas o no asimila los aprendizajes (Varela y Álvarez-Uría, 1991: 212-213). Frente a los trabajos previos de los médicos alienistas, Binet y Simon propondrán una nueva clasificación de los niños anormales basada en su relación con la escuela ${ }^{4}$. En estos trabajos, aparece por primera vez definida la noción de rendimiento escolar para juzgar los efectos de la acción de las escuelas y de las pedagogías especiales sobre los llamados anormales. Distinguen así el rendimiento escolar o pedagógico, entendido como «el grado de instrucción que un establecimiento logra dar a sus alumnos, después de tanto tiempo, y con un gasto de tanto" (Binet y Simon, 1907: 170), del rendimiento social, entendido como "la clasificación de los alumnos en la sociedad», «su utilización social» (Binet y Simon, 1907: 171). Estas nociones son difundidas en España, entre otros, por personajes como G. Rodríguez Lafora, en relación con la educación de los «anormales» 5 .

4. Sobre la trayectoria de Binet y la invención de la escala, puede verse Pinell (1995). En Cerezo y Luján (1988), se encuentra un recorrido histórico y una crítica de los presupuestos del concepto de inteligencia.

5. Gonzalo Rodríguez Lafora (1886-1971) fue un célebre neurólogo y psiquiatra español. En 1917, escribió Los niños mentalmente anormales. En 1925, creó el Instituto MédicoPedagógico y el Sanatorio Neuropático de Carabanchel. Tuvo un papel muy importante en la institucionalización de la psiquiatría y la psicología antes de la guerra, cuando tuvo que exiliarse. 
Estos trabajos convierten la escuela elemental en su laboratorio e invitan a establecer una colaboración entre médicos y docentes: el maestro debe alertar sobre una posible anormalidad juzgada según la relación del alumno con las normas escolares. Se trata de distinguir entre los anormales de la inteligencia («idiotas», «imbéciles», «débiles»), los anormales del carácter («inestables») y los falsos anormales («ignorantes sin deficiencia intelectual»; Huertas, 1998: 133 y 143). Los trabajos de Binet y Simon, a pesar de su efecto reificador y normalizador, buscaban, no obstante, distinguir a los «anormales» educables, cuyo retraso escolar podía «recuperarse» («anormales de escuela»), de los no educables («anormales de hospicio»), defendiendo para los primeros la escolarización en clases especiales en lugar del internamiento. En España, las instituciones de la «infancia anormal» conocerán un desarrollo menor que en Francia, frenado además por la guerra.

La noción de rendimiento escolar, metáfora física y económica transferida al ámbito escolar, se empieza a aplicar a todos los alumnos. La psicología insiste en la necesidad de su control y medición, junto con el nivel mental de los estudiantes, para "diagnosticar» sus "progresos» y conocerles "científicamente», al tiempo que se insiste en que el niño debe ser el centro de la escuela (Claparède, 1920: 145; Claparède, 1921: 300). Las principales corrientes de renovación pedagógica en España a principios de siglo se oponen al examen tradicional (oral, público, externo), pero defienden el examen basado en la ciencia psicopedagógica y en la apreciación científica del desarrollo infantil (Mainer, 2002: 118). Paradójicamente, este impulso por poner al niño «en el centro" y conocerle mejor favorece la individualización de las causas del rendimiento escolar.

En esos estudios psicopedagógicos, se fragua la categoría de retraso escolar, entendida como la discordancia entre la edad cronológica del niño y su «nivel mental», tal y como lo reflejaría su grado de instrucción ${ }^{6}$. Antecedente directo de la categoría de «fracaso escolar» (Ravon, 2000), no cobra sentido más que en relación con una organización escolar que establece un orden progresivo por estadios sucesivos con pretensión de universalidad para todos los niños, donde cada edad se asocia naturalmente a un grado de instrucción. La graduación escolar, concebida en la universidad y posteriormente extendida a la educación secundaria, se traslada así a la educación primaria desde principios del siglo $\mathrm{XX}$ (Viñao, 2002: 52 y s.). En esta transformación de la forma escolar, influida por la psicología, la pedagogía y la organización científica del trabajo, la clasificación de la infancia se vuelve una preocupación central. El ideal mítico de homogeneidad se buscará entonces aplicando diversos criterios de clasificación y las correspondientes pruebas o test (Viñao, 1990: 84-85).

6. Al tomar como medida de la inteligencia el «grado de instrucción», la escala métrica de inteligencia de Binet y Simon naturalizaba las normas escolares (Pinell, 1995). De manera general, las distintas categorías de niños «anormales» que emergen con la imposición de la obligatoriedad escolar se definen a partir de la norma escolar, naturalizándola (Muel, 1975; Pinell y Zafiropoulos, 1983; Varela y Álvarez-Uría, 1991). 
Se clasificará a los niños no solo en función de su nivel de inteligencia, sino también de su progreso escolar, como alumnos retrasados, adelantados o normales, y se crearán las primeras aulas especiales para alumnos «retardados» (Reglamento de escuelas graduadas de 1918; Viñao, 1990: 89). En ellas acabaron en la práctica los «retrasados» con respecto a su "grado normal», los "retrasados mentales», los «torpes» o los «niños difíciles» (Viñao, 1990: 89-90), en principio con la excepción de los «deficientes profundos», enviados a instituciones específicas por no considerarse educables.

El retraso escolar también preocupa a los médicos, que participan en el movimiento de protección de la infancia desde finales del siglo xIx. En el primer tercio del siglo XX, se desarrolla el campo de la higiene escolar y se llama la atención sobre los defectos físicos como causa de bajo rendimiento o retraso, por lo que se reclama una inspección médico-escolar para la vigilancia y el cuidado físico de los niños (Luzuriaga, 1919). Se van perfilando así una serie de actores (médicos, psiquiatras, psicólogos, pedagogos) que se sumarán a los propiamente escolares o administrativos, con el fin común de garantizar el máximo rendimiento infantil en la escuela.

Las primeras referencias a los éxitos y a los fracasos escolares —en plural—, ya en la década de 1930, aparecen en la prensa asociados a trabajos de especialistas de la inteligencia. Se empieza también entonces a relativizar el peso de la inteligencia, y se señalan otras posibles causas además de la anormalidad mental: «De ordinario, se cree que el niño inteligente tiene éxitos en la escuela y que el no inteligente fracasa. Esto es verdad, mas no siempre se puede deducir del éxito escolar una superioridad intelectual» («El examen de la inteligencia», 1932). Puntuales, estos usos anuncian un inicio de desplazamiento en la atribución causal de los éxitos y de los fracasos en la escuela: se consagra la importancia de la inteligencia, pero se abre la puerta a otros factores, lo que permite llamar la atención sobre los niños bien dotados — sin «deficiencia»- que fracasan. Este tema se retomará y se desarrollará después de la guerra.

En un contexto en el que la mitad de la población era analfabeta o semianalfabeta y la mayoría no completaba la escolaridad obligatoria, con aulas de alrededor de sesenta alumnos de distintas edades y niveles, una alta irregularidad en la asistencia a la escuela, un persistente trabajo infantil y un abandono generalizado del sistema educativo a partir de los 10 u 11 años (Viñao, 2004: 211-233), aparecían como problemas públicos la extensión de la escolarización primaria, la lucha contra el analfabetismo, la protección de la infancia o la cuestión de los «niños anormales», pero no aún el «fracaso escolar».

\section{Génesis del problema: del auge de las «inadaptaciones» al modo de educación tecnocrático}

Durante el primer franquismo, se prioriza la transmisión de una ideología y de una moral nacionalcatólica basada en los principios del Movimiento Nacional. La depuración o el exilio de parte de los pedagogos y de los psicólogos especializados en el rendimiento escolar y los problemas juveniles hace que predomine 
una orientación escolástica en estas disciplinas hasta los años cincuenta, cuando empiezan a desarrollarse nuevas corrientes (Delval, 1976; Carpintero, 2004).

Una explosión similar de expertos en infancia y juventud, instituciones y nuevas categorías de jóvenes "con problemas» a la que se da en Francia (MuelDreyfus, 1983: 238 y s.) tiene lugar en España de forma un poco más tardía. Desde las décadas de 1950 y 1960, aflora una literatura creciente de expertos alrededor de las dificultades escolares y las «inadaptaciones» de la infancia y la adolescencia (ver cronología en anexo). Estas obras, primero importadas de Francia, Bélgica y Estados Unidos, introducen la expresión fracaso escolar en España, sin asociarse aún a la compleción de la educación obligatoria.

Ello está relacionado con las transformaciones del sistema escolar que preceden a la reforma de 1970. Desde los años cincuenta, pero sobre todo en los sesenta, se da un fuerte incremento en las matriculaciones de bachillerato que se traduce en un mayor número de suspensos en las distintas pruebas y reválidas (Viñao, 2004: 239-240). El acceso de nuevas poblaciones menos ajustadas a las exigencias escolares de una enseñanza de tradición fuertemente selectiva hace que crezcan y se hagan más visibles los «fracasos» de los estudiantes. Los «fracasos escolares», en plural, empiezan a aparecer como un fenómeno masivo, aunque no se conciban aún como un problema de sociedad ${ }^{7}$.

\subsection{De "anormales» a «inadaptados»: la medicalización y la psicologización del fracaso escolar en la postguerra}

Los médicos tendrán una gran importancia en el diagnóstico y en la gestión de los «fracasos escolares». Desde los años cuarenta, se multiplican, en la prensa y en las revistas, las llamadas a una colaboración médico-pedagógica para asegurar el «máximo rendimiento escolar del alumno» a través de una «medicina correctiva» atenta a las patologías de la edad escolar (defectos sensoriales, posturales, enfermedades, constitución; «El Dr. Barnosell en el colegio La Salle Bonanova», 1953), continuando con la tradición del campo de la higiene escolar. A ello se añaden los intentos de regulación y corrección de las prácticas cotidianas de alimentación, reposo y cuidado en la salud de los hijos.

Estas formas de medicalización se acentúan en las décadas de 1950 y 1960, con las charlas dadas por algunos expertos médicos y psiquiatras en colegios o instituciones de formación de maestros y psicólogos, o la multiplicación de artículos divulgativos dirigidos sobre todo a las madres y firmados por médicos, que tienen como objetivo «educar» a las familias para el cuidado físico, mental y afectivo de sus hijos. Se insiste en las cuestiones médicas y fisiológicas, aunque integrando las psicológicas y afectivas: «En nuestros días los fracasos escolares son tanto un asunto médico como un problema que interesa a los profesores.

7. Usamos el término masivo para referirnos al hecho de que afecta a proporciones importantes de población, no necesariamente a la «mayoría» de ella. Como veremos, el fenómeno aparece como masivo en un momento en el que su peso cuantitativo era menor que en épocas anteriores, pero su cuantificación y visibilización era mayor. 
Muy a menudo, en efecto, sus causas son fisiológicas; no es raro tampoco que intervengan factores psicológicos» (Soubiran, 1968).

Se trata de incidir en las prácticas y en los ambientes familiares para asegurar las condiciones de «higiene física y mental» necesarias para el máximo rendimiento escolar del niño: "¿Tiene su hija buena vista?», "¿Oye bien?», "iRespira bien?», "iCome convenientemente y es regular su ritmo de vida?», «Piensa usted en el desayuno?» (Soubiran, 1968); «un descanso nocturno prolongado es indispensable», "las calorías en exceso no son buenas», «los defectos del oído y de la vista» afectan al estudio, "hay que evitar el sentimiento de frustración», "Es muy importante la higiene dental» (De Aichelburg, 1970). Tomando como objeto la mejora del rendimiento escolar, se intenta inculcar todo un modo de vida y un ideal de salud, regulando las "conductas que se ejercen en la intimidad del hogar» (Boltanski, 1974: 14-15).

Estos consejos para padres localizan las causas del problema en la fisiología del niño, en sus capacidades intelectuales, en los cuidados o en la afectividad paternos, es decir, en el alumno y la familia, fuera de la escuela (aunque puntualmente se aluda al exceso de contenidos y a la presión por los exámenes). El diagnóstico y la solución están, sin embargo, en manos del médico como experto en infancia:

No hay niños perezosos, afirma un eminente doctor; sólo hay niños inadaptados. ¿¿De quién es la culpa? Ciertamente, no de los niños y apenas de los padres, con demasiada frecuencia mal informados o apegados a las ideas anticuadas sobre la educación. La pereza es, ante todo, un asunto del médico; se empieza a comprender esto y a auxiliar a los alumnos que han sido tachados con demasiada ligereza y durante demasiado tiempo de «vagos». (Soubiran, 1967)

El consejo médico-psicológico actúa así individualizando el problema y manteniéndolo como cuestión privada de las familias (a pesar del carácter masivo del mismo que ya expresaban las cifras de suspensos en secundaria) y soluble a través del tratamiento médico individualizado o la modificación de las prácticas familiares: «De usted depende el éxito de su hijo en los estudios», "No haga usted de su hijo inteligente un retrasado escolar», se titulan algunos de estos artículos.

En las décadas de 1940 y 1950, crece entre los expertos de la infancia el interés por los alumnos «inteligentes» — sin «deficiencia intelectual»— que fracasan en la escuela. Pero, frente al interés por las relaciones entre rendimiento académico e inteligencia de principios de siglo, parece darse una inflexión hacia otros factores, matizando el predominio de la inteligencia como factor explicativo, sin cuestionarla o desecharla. Detrás de la pereza, habría un problema de carácter más que de aptitud mental (De Buck, 1959) o, según la neuropsiquiatría infantil, «trastornos intelectuales o de carácter» con base en un desequilibrio fisiológico o neurobiológico (Robin, 1954). De la descripción de los perezosos, se excluye, no obstante, a los «retrasados mentales» (Robin, 1954: 17). 
Pero también se argumenta que «casi siempre intervienen problemas afectivos en las dificultades escolares», provengan estos «del sujeto mismo o del medio perturbadon (Mauco, 1952: 6). En esta idea, persistente hasta hoy con variaciones, influye la difusión creciente del psicoanálisis y la psicoterapia. No es raro, además, que se culpe de ello a la educación familiar: «La debilidad en la educación, el abdicar ante el niño y la excesiva solicitud, son responsables de un síndrome muy importante en el estudio de los retrasados escolares: el retraso afectivo" (Robin, 1954: 41). "La comprensión de los padres es fundamental», pero «la excesiva protección puede ser perjudicial» (De Aichelburg, 1972). Es decir, se condena en los padres tanto el «abandono» de sus hijos como la excesiva exigencia en cuanto a resultados escolares o la «sobreprotección».

Así, desde finales de los años cincuenta, los psiquiatras insisten en que el fracaso escolar es, en realidad, el sintoma o la exteriorización de un problema de personalidad o de un problema afectivo de origen familiar. Se da una importancia creciente al ambiente como fuente de perturbaciones en la «adaptación» del niño. La herencia sería una variable fija, apenas se podría modificar; el ambiente sería la causa de la mayoría de trastornos y la variable sobre la que intervenir («El doctor Folch y Camarasa, en el colegio San Miguel», 1956). El «trastorno» del rendimiento escolar sería producto de una "carencia afectiva» por falta de «cohesión familiar» (Méndez, 1958).

Los discursos sobre la inadaptación y la higiene mental identifican, por tanto, la familia —en particular, su componente afectivo—, más que el medio escolar, como origen de la «inadaptación escolar» y del «rendimiento deficiente»: «Para que un niño trabaje bien es necesario que viva una vida familiar feliz. Muchos niños inteligentes pero vagos son el resultado de hogares donde reina la discordia» (Soubiran, 1968). Definen las "patologías» del medio familiar (desatención, permisividad, sobreexigencia o sobreprotección) a partir de un modelo idealizado de familia nuclear conyugal, afectivamente integrado, sin conflictos, ocultando además la relación de las «dificultades escolares» con la clase social de origen y el capital cultural del hogar. A pesar de los desplazamientos en las formas de explicar los fracasos y los retrasos escolares, conviven de forma ambivalente las explicaciones psicológicas que los remiten a la inteligencia, al carácter o a la afectividad (la patologización del individuo o de su medio social y familiar), con las explicaciones de herencia somaticista, que los remiten a lo orgánico.

En los años cincuenta y sesenta, se reclasifican en parte los retrasos y los fracasos como inadaptación, multiplicándose las referencias en la prensa y en las revistas educativas a la «inadaptación de la infancia y la juventud», la «inadaptación escolar»o la «inadaptación social». Esta nueva noción, elaborada por especialistas del sector $p s i$, abarcará las categorías de los «deficientes físicos» y "psíquicos», así como los niños que, sin tener esas «limitaciones», sufren "perturbaciones afectivas» o "anomalías inherentes al temperamento" que se podrían manifestar, entre otros, en fracasos escolares (Wall, 1963: 285). Esta ampliación del campo de la inadaptación extiende la preocupación por la inadaptación escolar y los fracasos más allá de la enseñanza primaria y de la 
infancia, coincidiendo con el proceso de apertura y «democratización» de la enseñanza secundaria e identificándose también con una representación de la adolescencia y la juventud como edad turbulenta en la que los jóvenes aparecen como sujetos sugestionables por el ambiente, tendentes a la irritabilidad, la agresividad, la depresión, las acciones «antisociales» ("gamberrismo», delincuencia) o los «trastornos del comportamiento». El referente de estos discursos son los nuevos públicos de clase media y popular que acceden entonces al bachillerato, que preocupan por sus fracasos escolares y por sus prácticas juveniles «inadaptadas».

Ello coincide con el desarrollo, además, de una psicología escolar con vocación práctica alrededor de los temas del rendimiento, los test, la psicometría, las fichas psicopedagógicas, etc., que se constituyó en disciplina específica con las primeras reuniones y los primeros congresos nacionales de psicología en los años sesenta. La psicología pugna por hacerse un lugar en el campo escolar. La orientación escolar, encuadrada a la vez en los presupuestos de la teoría del capital humano y de las psicologías de la inadaptación (Varela y Álvarez-Uría, 1991: 268-270), conoce un gran desarrollo y se integra en el sistema educativo, consagrándose con la Ley General de educación (LGE). En paralelo, en esa misma década, se multiplican las instituciones privadas de psicología y de psicopedagogía que tratan el «fracaso escolar» o los "problemas del rendimiento escolar», ofreciendo servicios de diagnóstico y orientación. También en los años sesenta se darán las primeras conferencias específicas sobre el «fracaso escolar» en España y a nivel internacional, en general deudoras de los enfoques psicológicos del «retraso escolar» y de la «inadaptación». Se perfila, así, un mercado del fracaso escolar que trasciende las instituciones educativas y en el que nuevos actores pugnan por hacerse un hueco.

\subsection{Los fracasos escolares como despilfarro de capital humano}

La década de 1960, en España, constituye un momento de cambio socioeconómico acelerado, bajo el gobierno tecnocrático del Plan Nacional de Estabilización Económica (1958). En el ámbito educativo, tiene lugar la llamada explosión escolar y se establecen las bases del sistema de enseñanza tecnocrático (Lerena, 1976).

Además, la relativa apertura de la enseñanza secundaria va a suponer una pérdida de la tradicional eficacia interna - baja tasa de abandonos y suspensos- de este nivel (Viñao, 2004: 237) y va a generarse cierta controversia alrededor de los exámenes, cuyo nivel de exigencia parece mantenerse frente a la diversificación del alumnado, lo que genera un aumento de los suspensos. A esto se añaden la demanda de una reducción de los programas frente a la «sobrecarga» de los niños y la crítica del «academicismo». Todo ello provoca que la atención en torno a los "fracasos escolares» se dirija primero a los suspensos en secundaria, mientras en primaria el foco sigue puesto en la universalización de la escolarización. Esta situación se mantiene hasta la implantación de la LGE. A pesar del aumento de la escolarización en secundaria, esta continúa 
Gráfico 1. Tasas de escolarización por edad y enseñanza (1970-1971)

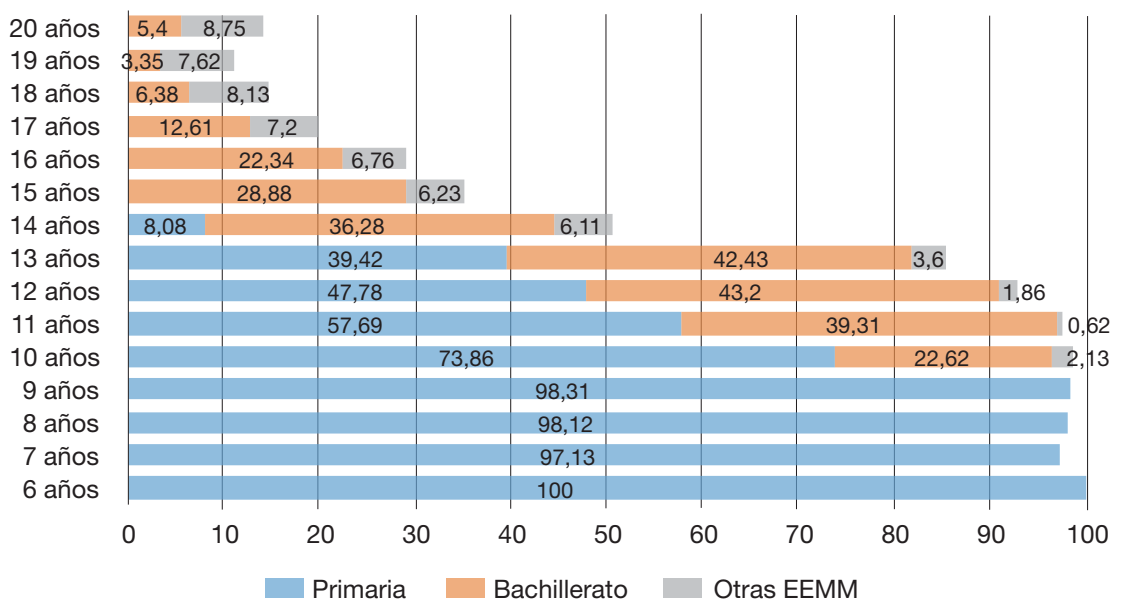

Fuente: elaboración propia a partir de CIDE (1992: 115, anexo 2).

alcanzando a una proporción muy baja de la población, por la estructura dual del sistema escolar (una primaria y una secundaria no integradas y segregadas por clase social; gráficos 1 y 2 ).

En esos años, se desarrolla la teoría del capital humano, que define la formación de la mano de obra como factor de impulso de la economía y la educación como una inversión. Basándose en estos presupuestos, se producen toda clase de indicadores de funcionamiento de los sistemas educativos, con el objetivo de medir su «eficacia» y promover una «mejor utilización» de los recursos humanos y un mayor ajuste de estos a las «necesidades» del mercado de trabajo. La producción de estadísticas educativas conoce una expansión sin precedentes en los años sesenta y setenta, con una atención creciente no solo a la escolarización y al acceso a los distintos niveles educativos, sino también a los resultados y al rendimiento académico del alumnado (titulación, exámenes, retraso escolar, repetición) ${ }^{8}$. Los fracasos escolares se construyen entonces como "pérdidas» o "despilfarro» (wastage) de recursos humanos (UNESCO, 1970). Este enfoque encontrará defensores en las organizaciones internacionales (UNESCO, OCDE) y en los gobiernos occidentales, incluido el gobierno tecnocrático del último franquismo.

8. Desde finales de la década de 1950 , la UNESCO organiza conferencias y produce recomendaciones para la elaboración y la estandarización de estadísticas de educación, lo que la convierte en un importante centro de cálculo (Latour, 1992). Si las estadísticas escolares comienzan a desarrollarse en España desde finales del siglo Xviı al servicio de la política ilustrada y centralizadora de la Administración, registrando el número de escuelas, alumnos, profesores, etc. (Guereña y Viñao, 1999), las primeras estadísticas sobre calificaciones escolares no aparecen casi hasta principios del siglo $\mathrm{xx}$, cuando empiezan a recogerse para bachillerato. Desde los años sesenta, estas estadísticas se han vuelto cada vez más centrales en la elaboración de políticas públicas. 
Gráfico 2. Población matriculada por enseñanza y clase social (1970)

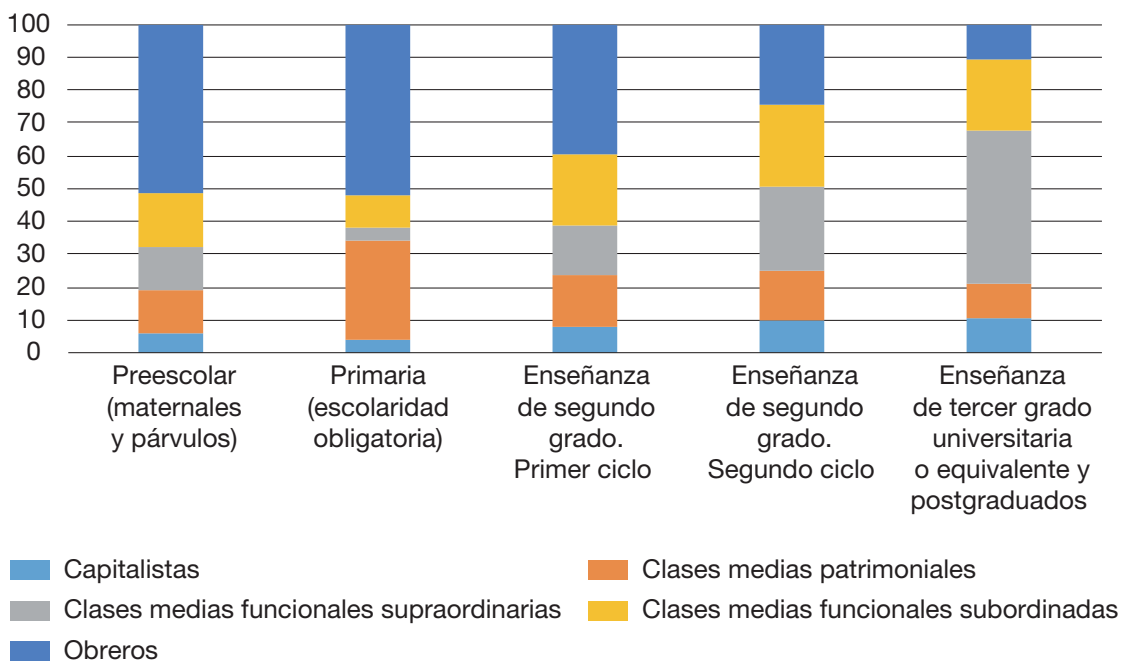

Fuente: elaboración propia a partir de INE, Censo de población de 1970, tomo iii, tabla 26, p. 111. Categorías tomadas de Torres Mora (1991).

La reforma de 1970 se fragua en este contexto internacional caracterizado por la «fe» en el desarrollo económico (Puelles, 1992: 17-18). La LGE, apoyada en el Libro blanco (MEC, 1969) elaborado por un equipo de expertos vinculados al ministerio Villar Palasí y a la UNESCO, romperá el sistema dual y establecerá un tronco común para toda la población de 6 a 14 años. Basada en abundantes estadísticas, la reforma mezclará la ideología economicista y tecnocrática de las teorías del capital humano con la búsqueda de una fundamentación psicológica (ajuste al «desarrollo psicobiológico del niño»), cierto humanismo cristiano y elementos de las pedagogías paidocéntricas y activas («espontaneidad», «creatividad», «responsabilidad»). De este modo, se legitima una reforma realizada por los técnicos del régimen, pero no por políticos del Movimiento, que recoge elementos tradicionales de este y elementos innovadores de las reformas educativas europeas de los años sesenta (Puelles, 1992), además de recurrir a las nociones de modernización y de igualdad de oportunidades (entendida predominantemente como igualdad de acceso a los distintos niveles del sistema educativo, en función de las "capacidades» y de las «aptitudes» de cada uno).

Además, la reforma refleja e institucionaliza una definición de la calidad y del rendimiento del sistema escolar. Como los de una fábrica o empresa, estos se miden por su "productividad», «eficacia» y «resultados» reflejados en diversos indicadores que hacen del rendimiento de los alumnos el rendimiento del sistema. Un sistema educativo eficaz, «bueno», lograría un ajuste entre la "productividad del sistema educativo» (número de titulados) y las «necesidades 
de recursos humanos» de un mercado de trabajo en cambio (MEC, 1969: 25) sin desperdiciar capital humano.

De forma secundaria, la reforma dará cierta importancia a las tasas de éxitos y fracasos en las distintas pruebas de secundaria, que aparecen como un problema de rendimiento y productividad del sistema que debe corregirse. Ante estos fracasos definidos como ineficacia del sistema y despilfarro de capital humano, se anticipa la orientación como posible solución: «Muchas dificultades y fracasos se evitarían, sin duda, si el alumno se sintiera asistido y tutelado en determinados momentos de su vida estudiantil, tanto en problemas concernientes al aprendizaje como en cualquier situación de tipo personal» (MEC, 1969: 25). La ley incorpora así parcialmente los discursos en circulación en el mundo experto sobre los fracasos y las dificultades escolares. Orientando a los alumnos a lo largo de sus trayectorias, se espera evitar que elijan estudios para los que no tendrían las «aptitudes» necesarias, reduciendo las «frustraciones» y los suspensos, además de contribuir a adaptar los «recursos humanos» a las necesidades de la modernización económica. Como otra solución a esos fracasos, se introdujeron también las enseñanzas de recuperación en $\mathrm{EGB}$ y $\mathrm{COU}$, aunque como mecanismo institucional aún no vinculado explícitamente al "fracaso escolar» y de aplicación y eficacia limitadas (Navarro, 1992: 212).

\subsection{El cuestionamiento de la ideología del don}

La LGE cuestionaba parcialmente la desigualdad de oportunidades, pero no lo que Bourdieu y Passeron (1970) llamaron la ideología del don —la ideología escolar que presenta las diferencias de capital cultural como don natural, naturalizando la desigualdad social- No obstante, en los años setenta, en España y en otros países europeos, esa ideología fue desacreditada desde varios frentes.

Uno de estos frentes fue la sociología. Los trabajos sociológicos que, en la década de 1960, se habían interesado por la educación se enmarcaban en una perspectiva cercana a la de la teoría del capital humano y la planificación educativa (Ortega, 1983). En parte como reacción, en los años setenta, se constituyó la sociología de la educación como subdisciplina, importando y desarrollando trabajos centrados en la crítica del sistema escolar como reproductor y legitimador de desigualdades de clases?

Ocurre $[\ldots]$ que la cultura escolar es una cultura de y para las clases dominantes, y que los procedentes de clases trabajadoras tienen otra cultura que esa [...] la presencia de este alumnado en las clases constituye una invitación a que se

9. Los herederos y La reproducción, de Bourdieu y Passeron, se traducen al castellano por primera vez en 1967 (prólogo de José Luis López Aranguren) y 1977 (prólogo de Marina Subirats), respectivamente; La escuela capitalista en Francia, de Baudelot y Establet, en 1975; La meritocracia y el "coeficiente de inteligencia", una nueva falacia del capitalismo y La instrucción escolar en la América capitalista, de Bowles y Gintis, en 1976 y 1981, respectivamente; El cociente intelectual, del psicoanalista Michel Tort, en 1977. 
desclasen, y, alternativamente, un ejercicio de sado-masoquismo: entran a la escuela como pobres, y salen de ella como pobres y, además, como tontos, esto es, no tienen vocación, no tienen aptitudes. Estos niños - la mayoría de los españoles — serán descalificados socialmente, [...] ahora con guante blanco: porque no han estudiado, porque no valían para otra cosa. Bajo la ficción de la neutralidad el aparato escolar consigue individualizar el problema: estos alumnos han fracasado. (Lerena, 1978)

El sistema escolar no solo reproduciría divisiones sociales, sino que también las legitimaría, haciéndolas aparecer como diferencias de capacidad individual.

Este cuestionamiento también tiene lugar desde la psicología, donde aparecen nuevos enfoques (psicoanalíticos, constructivistas, etc.), algunos de ellos críticos con las psicologías previas del retraso escolar y la inadaptación y con la noción hasta entonces predominante de inteligencia:

[...] en la práctica, la vida intelectual y la vida afectiva andan juntas. [...] Y es difícil saber, en realidad, qué es la inteligencia. [...] ninguno de esos cocientes es lo suficientemente aséptico como para que el resultado de aplicar los test deje de estar interferido por la vida emocional. [...] Una gran cantidad de fracasos escolares se debe a problemas emocionales. En estos casos, no hay métodos pedagógicos para resolver tales fracasos. Se deben emprender experiencias emocionales correctivas: psicoterapia, asistencia... Los niños que tienen problemas escolares suelen ser los más angustiados. La armonía de la persona, incluso los éxitos en la vida, está en función de una vida emocional sana. (García Pérez, 1976)

La psicología insiste en la necesidad de desculpabilizar a los propios alumnos de sus fracasos y desplaza la explicación de las deficiencias intelectuales a las relaciones afectivas, a los tipos de personalidad, a las «dificultades personales», a las actitudes de padres y docentes, al contexto escolar (desde enfoques piagetianos, se reitera que la escuela no se adapta al desarrollo intelectual del niño) o a los «hándicaps» socioculturales (Stambak, 1975; López, 1975; Simó, 1977; Roc y Solé, 1977; Equipo VII, 1979; Gayola et al., 1980). Tiende así a realizar otra forma de individualización y psicologización: sitúa la responsabilidad del fracaso fuera del alumno, pero como resultado de relaciones interpersonales, afectivas o de una relación personal del niño con la escuela.

Finalmente, también se cuestiona la ideología del don desde los movimientos de renovación pedagógica y organizaciones afines, que se apropian de parte de los discursos producidos por estas disciplinas en la formulación de sus críticas y exigencias de reforma. Entre ellos, las «alternativas» que se organizaron en torno a la idea de la nueva escuela pública se proponen «acabar con el carácter clasista de la enseñanza de modo que el fracaso escolar no recaiga siempre sobre las clases sociales dominadas» y rechazan «la idea de una inteligencia innata que explicaría el éxito escolar diferencial» (Feito, 2011: 38).

Entre las condiciones de posibilidad de toda esta producción simbólica, están el propio desarrollo de las ciencias sociales y las ciencias de la educación, 
así como la recomposición del espacio público y del campo político tras el franquismo. No obstante, si los sociólogos parecen centrarse en el análisis y en la interpretación, como mucho en la crítica y en la recomendación de políticas, los psicólogos y los movimientos pedagógicos ofrecen intervenciones contra el problema a nivel individual.

El aumento de las llamadas nuevas clases medias en los años sesenta y setenta se relaciona doblemente con la problematización del «fracaso escolar». Por un lado, se da una intensificación del uso del sistema escolar por parte de las clases populares, pero también de las viejas clases medias y las clases altas: grupos sociales que no habían requerido hasta entonces del sistema escolar para mantener su posición en el espacio social deberán ahora pasar por él (Bourdieu, 1979: 166-167). Emergen entonces una serie de profesiones basadas en la reconversión del capital cultural familiar: profesiones intelectuales, "oficios de consejo», "profesiones pedagógicas y parapedagógicas», etc. (Bourdieu, 1979: 169), que tienden a imponer sus normas a través de una dominación suave. En parte, a ello se debe la emergencia de nuevos expertos y profesionales de la infancia y la adolescencia interesados por las «inadaptaciones» y las dificultades escolares. Por otro lado, para que determinados actores consigan imponer un problema como problema social y público, deben tener los medios para ello (Lenoir, 1990), es decir: una posición social que dé acceso a determinados recursos y espacios de producción de discursos públicos. Las nuevas clases medias disponen del capital cultural y de las plataformas profesionales necesarios para hacer ver problemas como el de las dificultades escolares como problema social.

\subsection{La imposición de una credencial minima y su cuantificación}

Una de las piezas fundamentales en la construcción del «fracaso escolar» como problema social fue el establecimiento de una credencial mínima, un título que, al finalizar una educación obligatoria ahora común de los 6 a los 14 años, certificase el «aprovechamiento» en la etapa: el graduado escolar. El «fracaso escolar» se asocia a la no titulación en educación básica justamente cuando el Estado, tras décadas de intentos fallidos, consigue generalizar la escolarización básica e imponer un título que la sancione.

El credencialismo se extiende históricamente de los niveles educativos superiores a los inferiores: si los títulos escolares se expedían en la enseñanza secundaria y universitaria, dando acceso a determinadas profesiones (y clases sociales), con el establecimiento del certificado de estudios primarios (CEP) en 1932 (Proyecto de Bases de la Enseñanza Primaria y Segunda Enseñanza, en MEC, 1991: 87), se trata de extender esta lógica de certificación escolar al nivel básico de enseñanza, con la intención de combatir el analfabetismo y con una voluntad política - que no se realiza en la práctica- de convertirlo en condición para ejercer derechos y acceder al mercado de trabajo (Ibáñez Martín, 1945: 269). No obstante, en los años sesenta, tras sucesivas normas buscando su extensión, aún se deplora el escaso valor social del título: no 
aportaría más oportunidades al que lo posee que al que no, ni sería «requisito indispensable» para ejercer derechos, formalizar contratos o desempeñar cargos (Navarro, 1960: 2). La extensión de la lógica credencialista hará que ese «mínimo cultural vital» (Muel-Dreyfus, 1983: 46) que se constituyó primero como un conjunto de saberes básicos para todos los ciudadanos de la nación sin necesidad de certificación oficial, deba acreditarse a través de un título expedido por el Estado, considerado mínimo y común a toda la población.

El establecimiento de un título mínimo puede contribuir, como se esperaba, a elevar el valor social de la enseñanza básica. No obstante, al insertarse en un sistema de credenciales preexistente, definiéndose en relación con el resto de títulos, y en un contexto de crecimiento de la escolarización, y al depender su demanda en el mercado de trabajo de las lógicas propias del campo económico, el título parece condenado desde sus inicios a la devaluación por la inflación de títulos escolares - o a limitar su poder de distinción a algunos sectores en el segmento inferior del mercado de trabajo (Cachón, 1991) $\mathrm{Su}$ introducción contribuye a desplazar hacia arriba la competición por el capital escolar, al tiempo que dificulta la compleción de la etapa a unas clases populares acostumbradas a una escolaridad corta y a una pronta inserción en el mundo laboral (sin necesidad de título).

Con frecuencia, los problemas sociales adquieren un nombre y una alta presencia pública justamente cuando se reduce su importancia cuantitativa. La importancia social del CEP era tan reducida que, a diferencia de lo que ocurriría después con el graduado escolar o el graduado en ESO, el porcentaje de certificados ni siquiera aparecía en las estadísticas oficiales ${ }^{10}$. En el curso 1970-1971, el 49,61\% de los jóvenes de 14 años estaba fuera del sistema escolar, y prácticamente solo quedaban escolarizados quienes cursaban enseñanzas medias (gráfico 1, más arriba). Los desescolarizados provenían fundamentalmente de las clases populares (clase obrera y clases agrarias), y los miembros de esas clases que lograban acceder a la educación postobligatoria eran progresivamente eliminados por el sistema escolar (gráfico 2, más arriba, y Fernández de Castro, 1986: 131). En 1981, justamente cuando el «fracaso escolar» se comienza a asociar a la tasa de graduación en EGB y se convierte en problema público, solo un $13 \%$ de la población de 14 años está desescolarizada (y de entre quienes están escolarizados en octavo curso de EGB, un tercio no obtiene el graduado escolar). A finales de la década de 1970, la proporción de jóvenes de 19 y 20 años sin la credencial mínima (antes de la LGE) era del $51 \%$ y pasó a un $18,3 \%$ una década más tarde (bajo la LGE), siendo mucho más alta en las clases populares que en el resto de clases (Fernández MellizoSoto y Martínez García, 2013: 22). Paradójicamente, por tanto, cuando más

10. Empiezan a consignarse datos sobre el CEP de forma sistemática en las estadísticas del Ministerio justamente cuando se aplica la LGE y las autoridades se interesan por registrar el paso del CEP al graduado escolar y al certificado de escolaridad y por evaluar el efecto de las campañas de alfabetización. 
gente llega a finalizar la educación obligatoria y el «fracaso escolar» se reduce a un tercio de quienes acaban, es cuando este cristaliza como problema social y público (y adopta este nombre). Sin embargo, hasta una década antes, en un estado anterior del campo escolar, sin recibir ese nombre ni gozar de la misma visibilidad, había sido mucho mayor.

El proceso de cristalización de un problema social no es un mero reflejo de "condiciones objetivas» o cambios demográficos, sino que está relacionado con la construcción de expectativas y normas sociales (Dorn, 1996). La cristalización del problema tiene lugar también cuando se comienza a generalizar el acceso al nivel siguiente: en 1980-1981, la mitad de la población de entre 14 y 16 años estaba escolarizada en bachillerato (un 33\%) y FP (un 22,9\%) (CIDE, 1992: 116), expansión que se acentuará a lo largo de la década de 1980 (MEC, 1994: 41). Los estudios medios, de ser unas décadas atrás «un surplus de formación, pasan a convertirse en la norma», de forma que tener solo la EGB aparece como un déficit (Martín Criado, 1998: 125 y 141) y no tener el graduado, como un déficit aún mayor.

Además, la cristalización del «fracaso escolar» como no graduación en la educación básica tuvo que ver con el desarrollo de dispositivos de objetivación y visualización del problema. Con la LGE, no solo se introdujo un título mínimo, sino también lo que se llamaría después la doble titulación: un título para quienes alcanzaran, a juicio de los docentes, los objetivos de la etapa (graduado escolar); un certificado de escolaridad para quienes no los alcanzaran (sin contar a quienes abandonaban antes de acabar). Excluyendo del bachillerato a quienes no conseguían el graduado, se contribuyó a incrementar la competitividad y la selección en la EGB (Carabaña, 2003: 22) ${ }^{11}$. Tiene lugar entonces una práctica fundamental en la constitución del «fracaso escolar» como realidad y problema: su cuantificación. Las tasas de graduados y certificados se empiezan a publicar curso tras curso desde 1973-1974 (MPD-INE, 1975), pero no será hasta alrededor de 1980 cuando empiece a etiquetarse la proporción de certificados como "tasa de fracaso escolar», y esta forma de cuantificación y nominación sea empleada por los propios técnicos del Ministerio de Educación (Fuentes, 1980).

La condición, por tanto, para que esta identificación tuviese lugar y cristalizase la noción de «fracaso escolar» como no compleción de la educación básica fue su objetivación en un indicador estadístico, su inscripción en un dispositivo que lo hiciera visible y fácilmente movilizable en los discursos públicos, en las noticias y en los informes expertos sobre la educación, es decir, en un móvil

11. Este incremento no fue producto únicamente de la introducción del título, sino también de un conjunto más amplio de transformaciones. Frente a las ideologías pedagógicas presentes en la ley, que acentuaban la "evaluación continua» y las metodologías activas basadas en la creatividad y la espontaneidad, tuvo lugar una «bachilleratización» de la EGB: se adoptaron «modos de evaluación y aprendizaje del bachillerato tradicional», aumentaron los repetidores a partir de sexto curso y las evaluaciones negativas, la «evaluación continua» se convirtió en una multiplicación de los exámenes escritos tradicionales y aumentaron los contenidos en extensión y academicismo (Viñao, 1992: 67 y 70-71). 
inmutable ${ }^{12}$. Las tasas de graduación al final de la EGB son, por tanto, una pieza fundamental en la producción del «fracaso escolar» ${ }^{13}$.

Aunque el Ministerio nunca publicó tal indicador con el nombre de «tasa de fracaso escolar», la presencia creciente del término desde los años sesenta y especialmente en los setenta en el ámbito experto, mediático y político facilitó que asociaran la etiqueta a la tasa de no graduación, primero, los críticos con la reforma de 1970 y, a continuación, los propios agentes políticos en el Gobierno, obligados a aceptar la realidad reflejada por las estadísticas y a ofrecer soluciones. Esta fijación en un indicador, no obstante, no anula los sentidos ni las connotaciones asociados a la noción de "fracaso escolar» (fracaso y frustración individual, suspensos, inadaptación, «carencia afectiva» y familiar, desviación), que persisten, sino que añade otros nuevos (ineficacia o injusticia del sistema escolar).

Los poderes públicos buscaron aumentar el nivel educativo de la población, extender una cultura "mínima», estableciendo un mecanismo burocrático de certificación, sin reparar en las contradicciones que ello suponía. Crear un título al final de una educación obligatoria recién ampliada y dividida en cursos y ciclos suponía dificultar al mismo tiempo su obtención, sobre todo entre quienes partían con desventaja. No bastaba con la obligación de permanecer un número determinado de años en las aulas, sino que hacía falta además demostrar lo aprendido, «merecer» el título que supuestamente acreditaría la adquisición de unos mínimos comunes. No obstante, la decisión sobre su concesión dependía del juicio docente en el último curso, cuya arbitrariedad reflejaban las diferencias por centros y provincias (Carabaña, 1983). Pero, además, al convertir el título en condición de acceso a la rama «noble» de la educación secundaria, el profesorado, al concederlo, no solo juzgaba a cada alumno merecedor o no del título, sino también como posible candidato o no a acceder al bachillerato o, al contrario, a la formación profesional. La LGE estableció, asimismo, la obligación de quedarse al menos un año en FP1 tras la EGB (con poco éxito), con intención de prevenir el abandono y alimentar a la FP con quienes no alcanzaran los objetivos de la EGB. La «democratización» se acompañó así del establecimiento de un filtro que contuviera parcialmente las aspiraciones de continuidad en secundaria que generaba la propia extensión de la escolarización (como venía pasando con las reformas de las enseñanzas medias desde principios de siglo; Viñao, 2004: 238-239).

12. Son móviles inmutables los artefactos o signos «móviles y transportables», combinables, pero a la vez estables, que produce el trabajo científico (gráficos, tablas, porcentajes, etc.). Estos artefactos funcionan como inscripción, es decir, como una forma que sirve de vehículo a una información que circula entre dos lugares de una red (Latour, 1992; Latour y Hermant, 1999). Contribuyen así a producir la realidad que describen como «hecho objetivo».

13. La tasa de "fracaso» se calculaba dividiendo el número de personas que recibían el certificado de escolaridad por el número de matriculados aquel año en el último curso de EGB (octavo), dejando fuera a quienes abandonaban antes de finalizar, pero incluyendo a los repetidores. Más adelante, además de esta tasa «directa» de fracaso, se empezó a emplear la "tasa bruta de graduación», tomando como denominador común el total de población en edad teórica de finalización (Lacasa, 2010). 


\section{5. "Fracaso escolar, fracaso del sistema»}

Con la aplicación de la LGE (completada en 1975), se incrementó la atención pública dirigida a la educación, al sistema educativo y sus defectos. En ello, tuvo un papel importante la redefinición del espacio público en el paso de la dictadura a la democracia: nacen los movimientos de renovación pedagógica, las revistas Perspectiva Escolar (1974), Cuadernos de Pedagogía (1975) o Infancia y Aprendizaje (1978); se crea El País (1976); se legalizan los sindicatos (1977), que desarrollarán sus secciones de enseñanza; etc. En el ámbito universitario, se institucionalizan los estudios de Psicología, Sociología y Ciencias de la Educación. Estas transformaciones del espacio académico, público y político propiciarán un clima de crítica a una ley que gozaba de una frágil legitimidad de partida, tanto en los medios más tradicionales del régimen como en los medios críticos y clandestinos que iban a irrumpir unos años después en el espacio público, a pesar de su papel modernizador y de la larga vigencia que finalmente tendría (Cabrera, 2007: 149).

En este contexto de finales de la década de 1970, se multiplican los actos y las publicaciones alrededor del «fracaso escolar» desde la psicología, la psiquiatría, la pedagogía, los sindicatos o los movimientos de renovación pedagógica. El «fracaso escolar» de los alumnos, agregado en una tasa estadística, es movilizado como evidencia de la falta de eficacia y "calidad» del sistema, pero también de su falta de igualdad, de su injusticia, de una "democratización» ilusoria, visible ahora en la división al final de la EGB (entre graduados y certificados, y entre bachillerato y FP).

El esquema fracaso escolar, fracaso del sistema que se populariza entonces juega de forma ambivalente con el fracaso del sistema escolar en términos absolutos y con el fracaso del sistema en términos relativos: de la LGE (o el «modelo" general que encarnaba) o de algunos de sus elementos. Ambos argumentos se mezclan en los discursos de crítica a la LGE. Se dan la mano, así, este discurso que señala el fracaso de la LGE y el sentido del «fracaso escolar» asociado al porcentaje de suspensos y de alumnos que no finalizan la EGB.

En los primeros años ochenta, el «fracaso escolar» cristaliza definitivamente como problema público. Se pasa definitivamente del plural (fracasos escolares) al singular genérico (fracaso escolar) en los discursos públicos, signo de un cierto cambio de percepción. Las primeras críticas al concepto (Delval, 1982; Carabaña, 1983) que aparecen entonces no impiden su consagración. Se da un reconocimiento oficial del problema y una apropiación por parte de los agentes estatales, que asumen la categoría como objeto de interés y de acción pública. En 1980, el inspector general de EGB califica las tasas de fracaso en esta etapa como "preocupantes, pero no alarmantes», explicándolas como una circunstancia coyuntural relacionada con la aplicación del tronco común (Fuentes, 1980). Unos meses más tarde, el director general de EGB anuncia una reforma de esta enseñanza para paliar sus «insuficiencias»: los programas renovados. La propuesta emplea las tasas de fracaso al final de la EGB como indicador de un rendimiento escolar insatisfactorio y de la necesidad de reformarla (MEC, 
1980; Caselles, 1981) ${ }^{14}$. En el debate sobre la reforma de las enseñanzas medias de 1981-1982, también se evalúan medidas para resolver el «fracaso escolar» (Fuentes, 1981; MEC, 1982).

Los usos políticos del concepto contribuyen, así, a la definitiva consagración del problema, pero también al desplazamiento de la responsabilidad (de alumnos y familias al sistema) y de su propiedad (de expertos de la infancia a políticos y movimientos en pugna ${ }^{15}$. El reconocimiento generalizado del problema y la presión creciente para la reforma del sistema escolar en los campos mediático y político hacen que se traslade su solución al campo burocrático (Ministerio) (Bourdieu, 1994). Los agentes estatales tratan de apropiarse del problema y, con ello, de su definición y de sus soluciones legítimas: frente a las «alternativas» al sistema escolar planteadas desde los movimientos de renovación pedagógica, los ministros de UCD tratan de modificar algunos de sus «fallos». Aunque en estas reformas aparece ya la noción de fracaso escolar como justificación, no será hasta más tarde cuando se elabore una política específica contra este.

\section{Conclusiones}

El «fracaso escolar», hoy problema indiscutible en España, no lo fue siempre: emerge como problema social en los años sesenta y setenta y cristaliza como problema público a principios de los ochenta. Ello tiene lugar tras un largo proceso de problematización del que hemos rastreado los antecedentes al menos hasta principios del siglo xx, con la invención del «rendimiento» y del «retraso» escolares. La génesis del problema es producto de una serie de discursos y de prácticas escolares, expertos, mediáticos, políticos, de un trabajo colectivo de enunciación y movilización de actores diversos relacionado con una serie de transformaciones sociales y escolares más amplias.

La aparición del término a finales de la década de 1950 en España y su difusión en las décadas de 1960 y 1970 toma apoyo en un campo de expertos de la infancia y la adolescencia entonces en redefinición y expansión, en un contexto de generalización de la educación básica, de apertura de la enseñanza secundaria y de creciente centralidad del capital escolar en la estructura social. Pero su definitiva asociación al porcentaje de no titulados en la educación básica tiene lugar al concluir la década de 1970, en un contexto de democratización del espacio público, de cuestionamiento de la ideología del don, de crecimiento de la escolarización y de las clases medias y de institucionalización de un modo de educación tecnocrático basado en una noción de calidad que vincula el rendimiento del sistema a su rendimiento cuantitativo en términos

14. Gonzalo Gómez Dacal, pedagogo e inspector, fue inspector general de EGB entre 1979 y 1982, durante el gobierno de UCD. Pedro Caselles Beltrán fue sucesivamente maestro, inspector, delegado y subdirector general de Centros, además de director general de EGB entre 1977 y 1982.

15. Tomamos los conceptos de propiedad y de responsabilidad de los problemas públicos de Gusfield (1984: 10-16). 
de producción de capital humano. Con la implantación de una enseñanza básica común para todos sancionada por una credencial y la contabilización de la proporción de estudiantes que no consiguen obtenerla, la no titulación aparece como el indicador privilegiado de un «fracaso escolar» que no será ya solo de los alumnos (o de sus familias), sino también de un sistema escolar objeto de críticas y de luchas crecientes. El término pasó así del sentido común al espacio público y al campo político, para volver a pasar al sentido común con este nuevo sentido.

Desde su cristalización como problema público, el «fracaso escolar» ha estado en el centro del debate educativo, siempre presente en la elaboración de políticas y reformas educativas, a la vez como objeto y legitimación de estas. Así, en las décadas siguientes, se convirtió en objeto de dispositivos que fueron segmentando la educación obligatoria, al tiempo que su extensión hasta los 16 años con la LOGSE dificultaba la titulación (especialmente entre las clases populares; Fernández Mellizo-Soto y Martínez García, 2013). Además, la internacionalización del problema en la década de 1990 y en los primeros años del siglo XXI introduce nuevas nociones e indicadores («abandono escolar temprano», Tarabini, 2015: 157, y «bajo rendimiento» en competencias PISA, Martínez García, 2009) que compiten y se mezclan con el concepto en el discurso público, sin llegar a sustituirlo o eliminarlo. Su carácter evidente y su carga moral - ¿quién puede estar en contra de luchar contra el «fracaso escolar»? - hacen de él un elemento estratégico en la pugna por definir la política educativa en una sociedad en la que el peso del sistema escolar en las estrategias de reproducción y reconversión no ha dejado de crecer.

\section{Referencias bibliográficas}

ARIÈs, Philippe (1972). L'enfant et la vie familiale sous l'Ancien Régime. París: Seuil. - (1986). «La infancia». Revista de Educación, 281, 5-17.

Boltanski, Luc (1974). Puericultura y moral de clase. Barcelona: Laia.

Bourdieu, Pierre (1979). La distinction: Critique sociale du jugement. París: Les Éditions de Minuit.

- (1994). Raisons pratiques: Sur la théorie de l'action. París: Seuil.

Bourdieu, Pierre y PAsSeron, Jean-Claude (1970). La reproduction: Éléments pour une théorie du système d'enseignement. París: Les Éditions de Minuit.

Cabrera, Blas (2007). «Políticas educativas en clave histórica: La LOGSE de 1990 frente a LGE de 1970». Témpora: Revista de Historia y Sociología de la Educación, $10,147-181$.

CACHón, Lorenzo (1991). «Segmentación del mercado de trabajo y niveles educativos». En: VVAA. Sociedad, cultura y educación: Homenaje a la memoria de Carlos Lerena Alesón. Madrid: CIDE-UCM, 111-136.

Carabaña, Julio (1999). «La pirámide educativa». En: Fernández Engutta, Mariano (ed.). Sociología de la educación: Lecturas básicas y textos de apoyo. Barcelona: Ariel, 720-738.

- (2003). De una escuela de mínimos a una de óptimos: La exigencia de esfuerzo igual en la Enseñanza Básica. Madrid: Fundación Alternativas. Documento de trabajo $32 / 2003$. 
Carpintero, Helio (2004). «Medio siglo de la psicología en España (1950-2000)». Revista Interamericana de Psicología = Interamerican Journal of Psychology, 38 (2), 343-350.

Cerezo, José Antonio y Luján, José Luis (1988). El artefacto de la inteligencia. Barcelona: Anthropos.

CIDE (1992). Las desigualdades en la educación en España. Madrid: MEC-CIDE.

Cuesta, Raimundo (2005). Felices y escolarizados: Crítica de la escuela en la era del capitalismo. Barcelona: Octaedro.

Dorn, Sherman (1996). Creating the Dropout: An Institutional and Social History of School Failure. Westport, CT: Praeger Publishers.

FEITO, Rafael (2011). Los retos de la participación escolar. Madrid: Morata.

Fernández de Castro, Ignacio (1986). Análisis de la actitud de rechazo de los alumnos al sistema educativo y de su incidencia en las enseñanzas medias. Madrid: CIDE.

Fernández Enguita, Mariano (1994). «El sistema educativo». En: Campo, Salustiano del (ed.). Tendencias sociales en España (1960-1990). Bilbao: Fundación BBV, 117-140.

Fernández Enguita, Mariano; Mena, Luis y Rivière, Jaime (2010). Fracaso y abandono escolar en España. Barcelona: Fundación LaCaixa.

Fernández Mellizo-Soto, María y Martínez García, José Saturnino (2013). "Increasing inequalities: Recent school failure trends in Spain». Seminario permanente del Departamento de Sociología VI (Sociología de la Educación). Universidad Complutense de Madrid, 21 de octubre.

Fundación Foessa (1970). Informe sociológico sobre la situación social de España 1970. Madrid: Euroamérica.

- (1983). Informe sociológico sobre el cambio social en España 1975-1983: IV Informe Foessa. Madrid: Euroamérica.

Guereña, Jean-Louis y ViñaO, Antonio (1999). «Estadística escolar, proceso de escolarización y sistema educativo nacional en España (1750-1850)». Boletín de la Asociación de Demografía Histórica, XVII (2).

Gusfield, Joseph R. (1984). The culture of public problems: Drinking-driving and the symbolic order. Chicago: University of Chicago Press.

Huertas, Rafael (1998). Clasificar y educar: Historia natural y social de la deficiencia mental. Madrid: CSIC.

IsAmbeRT-Jamati, Viviane (1992). "Quelques rappels de l'émergence de l'échec scolaire comme "problème social" dans les milieux pédagogiques français». En: PIERrehumbert, Blaise (ed.). L'échec à l'école, échec de l'école. París: Delachaux \& Niestlé.

LACASA, José Manuel (2010). «Calcular el fracaso». Blog del IFIE (Instituto F de Investigación Educativa) [en línea]. <http://blogdelifie.blogspot.com.es/2010/11/calcularel-fracaso.html> [Consulta: 23 junio 2015].

Latour, Bruno (1992). Ciencia en acción: Cómo seguir a los científicos e ingenieros a través de la sociedad. Barcelona: Labor.

Latour, Bruno y Hermant, Émilie (1999). «Esas redes que la razón ignora: laboratorios, bibliotecas, colecciones». En: García Selgas, Fernando y Monleón, José (eds.). Retos de la postmodernidad. Madrid: Trotta, 161-183.

Lenoir, Remi (1990). «Objet sociologique et problème social». En: Champagne, Patrick; Lenoir, Remi; Merllié, Dominique y Pinto, Louis. Initiation à la pratique sociologique. París: Dunod.

Lerena, Carlos (1976). Escuela, ideología y clases sociales en España: Crítica de la sociología empirista de la educación. Barcelona: Círculo de Lectores, 1989. 
Mainer, Juan (2002). «Pensar históricamente el examen, para problematizar su presente: Notas para una sociogénesis del examen». Gerónimo de Uztariz, 17-18, 107-135.

Martín Criado, Enrique (1998). Producir la juventud: Crítica de la sociología de la juventud. Madrid: Istmo.

Martínez García, José Saturnino (2009). "Fracaso escolar, PISA y la difícil ESO». Revista de la Asociación de Sociología de la Educación, 2 (1), 56-85.

MEC (1991). Historia de la educación en España. Vol. 4, La educación durante la Segunda República y la Guerra Civil. Madrid: MEC.

- (1994). Estadística de la enseñanza en España 1990/91: Preescolar, general básica y EEMM. Madrid: Ministerio de Educación.

Morel, Stanislas (2010). L'échec scolaire en France (1960-2010): Sociologie d'un champ d'intervention professionnelle. París: EHESS. Tesis doctoral.

Muel, Francine (1975). "L'école obligatoire et l'invention de l'enfance anormale». Actes de la recherche en sciences sociales [en línea], 1 (1), 60-74. $<$ http://dx.doi.org/10.3406/arss.1975.2450>.

Muel-Dreyfus, Francine (1983). Le métier d'éducateur: Les instituteurs de 1900, les éducateurs spécialisés de 1968. París: Les Éditions de Minuit.

Navarro, Ramón (1992). "La ley Villar y la formación del profesorado». Revista de Educación, número extraordinario: «La LGE veinte años después», 209-236.

Ortega, Félix (1983). «La sociología de la educación en España». En: Informe sociológico sobre el cambio social en España 1975-1983: IV Informe Foessa. Madrid: Euroamérica, 165-182.

Perrenoud, Philippe (1990). La construcción del éxito y del fracaso escolar: Hacia un análisis del éxito, del fracaso y de las desigualdades como realidades construidas por el sistema escolar. Madrid: Morata.

Pinell, Patrice (1995). "L'invention de l'échelle métrique de l'intelligence». Actes de la Recherche en Sciences Sociales [en línea], 108 (1), 19-35. <http://dx.doi.org/10.3406/arss.1995.3145>.

Pinell, Patrice y Zafiropoulos, Markos (1983). Un siècle d'échecs scolaires (18821982). París: Les Éditions Ouvrières.

Puelles, Manuel de (1992). «Tecnocracia y política en la reforma educativa de 1970». Revista de Educación, número extraordinario: «La LGE veinte años después», 13-29.

- (2000). «Política y educación: Cien años de historia». Revista de Educación, número extraordinario: "La educación en España en el siglo xx», 7-39.

Ravon, Bertrand (2000). L'«échec scolaire»: Histoire d'un problème public. París: InPress.

Rujas, Javier (2015). Sociología del «fracaso escolar» en España: Construcción y gestión de un problema social. Madrid: Universidad Complutense de Madrid. Tesis doctoral.

Tarabini, Aina (coord.) (2015). Políticas de lucha contra el abandono escolar en España. Madrid: Síntesis.

Tezanos, José Félix (2001). «La estratificación social en España». En: CAmpo, Salustiano del (ed.). Perfil de la sociología española. Madrid: La Catarata, 109-161.

Torres Mora, José Andrés (1991). «Demografía educativa en los años ochenta: El nacimiento de una meritocracia bastarda». Educación y Sociedad, 8, 25-58.

Varela, Julia y Álvarez-Uría, Fernando (1991). Arqueología de la escuela. Madrid: La Piqueta.

VIÑAO, Antonio (1990). Innovación pedagógica y racionalidad cientifica: La escuela graduada pública en España (1898-1936). Madrid: Akal. 
- (1992). «La Educación General Básica: Entre la realidad y el mito». Revista de Educación, número extraordinario: "La LGE veinte años después», 47-71.

- (2002). Sistemas educativos, culturas escolares y reformas: Continuidades y cambios. Madrid: Morata.

- (2004). Escuela para todos: Educación y modernidad en la España del siglo XX. Madrid: Marcial Pons, Ediciones de Historia.

\section{Documentos}

Aichelburg, Ulrico de (1970). «Revisión médica del estudiante: Consejos para la salud física y mental de los niños a su regreso al colegio». Blanco y Negro (17 octubre), 68 .

- (1972). "El "shock" del primer día». Blanco y Negro (28 octubre), 77.

Binet, Alfred y Simon, Théodore (1907). Les enfants anormaux: Guide pour l'admission des enfants anormaux dans les classes de perfectionnement. París: Armand Collin.

Buck, Jean Marie de (1959). Ante el fracaso escolar de vuestros hijos. Bilbao: Desclée de Brouwer.

Carabaña, Julio (1983). "Le llamaban "fracaso escolar"». Cuadernos de Pedagogía, 103-104, 26-30.

Caselles, Pedro (1981). «Una reforma alentadora». El País (8 noviembre), 10-11.

Claparède, Edouard (1920). «La escuela y la psicología experimental (I)». Boletín de la Institución Libre de Enseñanza, XLIV (727), 297-303.

- (1921). "La escuela y la psicología experimental (II)». Boletín de la Institución Libre de Enseñanza, XLVII (763), 143-150.

Delval, Juan (1976). "Psicología y educación antes y después de la Guerra Civil». Cuadernos de Pedagogía. Suplemento número 3: "Fascismo y educación», 38-39.

- (1982). «Un concepto dramático e intencionadamente confuso». El País. Suplemento de Educación, 18.

«El examen de la inteligencia» (conferencia). La Vanguardia (23 abril 1932), 10.

«El doctor Folch y Camarasa, en el colegio San Miguel» (conferencia). La Vanguardia Española (8 marzo 1956), 15.

«El Dr. Barnosell en el colegio La Salle Bonanova» (conferencia). La Vanguardia Española (25 abril 1953), 14.

Equipo VII (1979). «Las raíces del fracaso escolar». Cuadernos de Pedagogía, 57.

Fuentes, Carmen (1980). «Las tasas del fracaso escolar, preocupantes, pero no alarmantes». $A B C$ (29 agosto), 24.

- (1981). «Presentado el proyecto de reforma de las Enseñanzas Medias». ABC (9 julio), 26.

García Pérez, Alfonso (1976). «La mayoría de los fracasos escolares está causada por problemas afectivos de los niños (Entrevista a la psicoanalista Mercedes Valcárcel)». El Pais (27 junio).

Gayola, Monique; Renau, María Dolores y Roig, Montserrat (1980). «Las raíces del fracaso escolar». Cuadernos de Pedagogía, 66.

IbÁÑez Martín, José (1945). «En torno a la nueva Ley de Enseñanza Primaria». En: MEC. Historia de la educación en España. Vol. 5, Nacional-catolicismo y educación en la España de posguerra. Madrid: MEC, 1990.

Lerena, Carlos (1978). «Escuela-criba y estructura de clases». El País (4 marzo).

López, Asunción (1975). "Patología del niño: Patología de la escuela». Cuadernos de Pedagogía, 12. 
Luzuriaga, Lorenzo (1919). «El cuidado de la salud de los niños en Inglaterra: Un problema de reconstrucción nacional». Diario El Sol (13 enero).

Mauco, Georges (1952). «Problèmes psychologiques de l'adolescence: Les échecs scolaires et les difficultés d'adaptation au niveau secondaire et supérieur en France». En: Conférence sur l'éducation et la santé mentale des enfants en Europe. París: UNESCO.

MEC (1969). La educación en España: Bases para una política educativa. Madrid: Ministerio de Educación y Ciencia.

- (1980). «Programas Renovados de la EGB (documento base)», Vida Escolar, 206, 3-15.

- (1982). Las enseñanzas medias en España: Resultados de la consulta. Madrid: MEC.

Méndez Domínguez, Luis (1958). «Lecciones del IV Congreso de Psiquiatría Infantil». La Vanguardia Española (15 julio), 16.

MPD-INE (1975). Estadística de la Enseñanza en España: Curso 1973-1974. Madrid: MPD-INE.

Navarro, Juan (1960). "Consideraciones sobre el Certificado de Estudios Primarios». Vida Escolar, 9, 2-4.

«Orden de 22 de abril de 1963 por la que se programa la distribución de las actividades escolares para aumentar la eficacia y rendimiento de las escuelas primarias». $B O E$, 102 (29 de abril de 1963).

«Real Decreto de 19 de septiembre de 1918, por el que se aprueba el Reglamento de régimen interior de las escuelas graduadas». Gaceta de Madrid, 274 (1 de octubre de 1918).

Roвın, Gilbert (1954). Las dificultades escolares en el niño y su tratamiento. Barcelona: Luis Miracle.

Roc, Mercé y Solé, María Rosa (1977). «Fracaso escolar y dislexia». Cuadernos de Pedagogía, 34.

Sánchez Sarto, Luis (ed.) (1936). Diccionario de pedagogía. Barcelona: Labor.

Simó, Roser (1977). "Fracaso escolar y dificultades emocionales». Cuadernos de Pedagogía, 30.

Soubiran, André (1967). «No hay niños perezosos». Blanco y Negro (30 septiembre), 99.

- (1968). «De usted depende el éxito de su hijo en los estudios». Blanco y Negro (1 junio), 105.

Stambak, Mira (1975). "La psicología y la escuela». Cuadernos de Pedagogía, 1.

UNESCO (1970). The statistical measurement of educational wastage (drop-out, repetition and school retardation). París: UNESCO.

WaLL, William D. (1963). Educación y salud mental. Madrid: Aguilar. 


\section{Anexo. Cronología (1950-1982)}

\begin{tabular}{cl}
\hline Año & Acontecimientos político-institucionales, publicaciones y actos académicos \\
\hline 1952 & España ingresa en la UNESCO. \\
& Creación de la Asociación Española de Psiquiatría del Niño y del Adolescente (AEPNYA). \\
& Conférence sur l'éducation et la santé mentale des enfants en Europe (UNESCO). \\
\hline $1954 \begin{array}{l}\text { Gilbert Robin. Las dificultades escolares en el niño y su tratamiento. Barcelona: Luis Mira- } \\
\text { cle. Ed. original en francés: } 1953.11 \text { ediciones en castellano. }\end{array}$ \\
\hline $1956 \begin{array}{l}\text { UNESCO. Causes of failure in school study plan. París: UNESCO. } \\
\text { International Meeting on Failure in School; Paris and Hamburg. }\end{array}$ \\
\hline $1958 \begin{array}{l}\text { Creación del centro de Documentación y Orientación Didáctica de Enseñanza Primaria } \\
\text { (CEDODEP). }\end{array}$ \\
IV Congreso de la Asociación Internacional de Educadores de Jóvenes Inadaptados. \\
Creación de la Association for the Evaluation of Educational Achievement (IEA). \\
IV Congreso de Psiquiatría Infantil (Lisboa).
\end{tabular}

1959 Plan de Estabilización Económica.

André Le Gall. Los fracasos escolares: diagnóstico y tratamiento. Buenos Aires: Eudeba. Ed. original en francés: 1954. 2 ediciones en castellano.

Jean Marie de Buck, S. J.. Ante el fracaso escolar de vuestros hijos. Bilbao: Desclée de Brouwer. Ed. original en francés: 1948. 2 ediciones en castellano.

1961 Creación de la OCDE.

Leo J. Brueckner y Guy L. Bond. Diagnóstico y tratamiento de las dificultades de aprendizaje. Madrid: Rialp. Ed. original en inglés: 1955. 14 ediciones en castellano.

1962 G. Mauco. Piscoterapia escolar. La inadaptación escolar y social y sus remedios. Madrid: Morata. Ed. original en francés: 1959. 2 ediciones en castellano.

W. D. Wall. Educación y salud mental. París: UNESCO. Ed. original en inglés: 1955.2 ediciones en castellano.

Conferencia de Juan Bosch Marín: «El problema de la adolescencia» (menciona «fracaso escola»" como síntoma de inadaptación social).

Conferencia de Georges Mauco: «La inadaptación escolar» (Instituto Municipal de Educación de Madrid).

Conferencia del doctor Folch Camarasa: «El fracaso escolar» (Clausura del Curso IX Cursillo de Psicología escolar aplicada, Barcelona).

1963 Inicio de la I Campaña Nacional de Alfabetización, que duró hasta 1968.

Orden 22 de abril 1963 (introducción de la noción de «curso» y de pruebas de promoción en primaria).

Orden de 10 de julio: convocatoria de ayudas económicas a niños y jóvenes con deficiencias e inadaptaciones de orden físico, psíquico o caracterial, con cargo al Fondo Nacional Para el Fomento del Principio de Igualdad de Oportunidades.

1964 Ampliación de la escolaridad obligatoria hasta los 14 años.

1965 Ley de Reforma de la Educación Primaria.

1966 Paule Parent, Claude Gonnet. Los escolares con problemas. Barcelona: Vicens-Vives. Ed. original en francés: 1965. 2 ediciones.

1967 Aprobación del Libro de Escolaridad en Enseñanza Primaria.

John Holt. El porqué del fracaso escolar. Buenos Aires: Troquel. Ed. original en inglés: 1964. 


\title{
Anexo. Cronología (1950-1982) (continuación)
}

Año Acontecimientos político-institucionales, publicaciones y actos académicos \\ 1969 Creación de los Institutos de Ciencias de la Educación. \\ MEC. La Educación en España. Bases para una política educativa. Madrid: MEC (Libro \\ Blanco). \\ J. Burniaux. El éxito escolar. Los estudios y los ocios de 13 a 17 años. Barcelona: Suceso- \\ res de Juan Gili, DL. Ed. original en francés: 1968. \\ W. Glasser. Escuelas sin fracasos. Buenos Aires: Paidós. Ed. original en inglés: 1968. \\ 2 ediciones. \\ N. C. Kephart. El alumno retrasado. Barcelona: Miracle. Ed. original en inglés: 1960. \\ 3 ediciones. \\ G. Avanzini. El fracaso escolar. Barcelona: Herder. Ed. original en francés: 1967. 5 edi- \\ ciones. \\ Congreso Mundial de Orientación. \\ Conferencia de Juan García Yagüe: «El fracaso escolar y sus causas». \\ Conferencia de Enrique Díez: «El fracaso escolar. Principios técnicos», Instituto Calasanz \\ de CC. de la Educación.
}

1970 Ley General de Educación.

W. D. Wall et al. El fracaso escolar. Buenos Aires: Paidós. Ed. original: UNESCO, 1962.

UNESCO. The statistical measurement of educational wastage (drop-out, repetition and school retardation). París: UNESCO.

Conferencia Internacional de la UNESCO, $32^{\mathrm{a}}$ sesión, Ginebra: «Improved effectiveness of educational systems, particularly through reduction of wastage at all levels of instruction".

1971 Orientaciones Pedagógicas.

G. Bastin. Por qué fracasan nuestros hijos. Madrid: Magisterio Español. Ed. original en francés: 1966.

1973 J. A. Ríos, M. A. Perearnau: Fracaso escolar y vida familiar. Madrid: Marsiega.

Curso: «El fracaso escolar en la infancia y adolescencia», San Sebastián.

OCDE. Les indicateurs de résultats des systèmes d'enseignement. París: OCDE.

1975 C. Gil Muñoz. Causas del fracaso escolar. Madrid: CVS.

Conferencia de Felisa Soriano: «Factores que influyen en el fracaso del escolar», Asociación de amas de casa.

1977 Pactos de la Moncloa.

J. Holt. El fracaso de la escuela. Madrid: Alianza. Ed. original en inglés: 1969. 4 ediciones en castellano.

Consejo de Europa. Educación Compensatoria. Madrid: MEC.

1979 L. Lurçat. El fracaso y el desinterés escolar en la escuela primaria. Ed. original francesa: 1976. 3 ediciones en castellano.

Jornadas Internacionales sobre Psicología y Educación.

1980 LOECE.

B. Martínez Muñiz. Causas del fracaso escolar y técnicas para afrontarlo. Madrid: Narcea. 3 ediciones. 
Anexo. Cronología (1950-1982) (continuación)

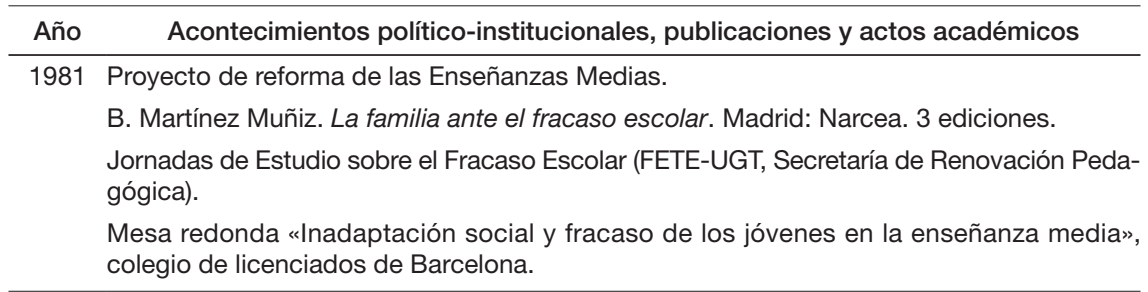

1982 Entrada de España en la UE.

Coloquio del Instituto de Estudios Sociológicos Bernard Krief sobre fracaso escolar.

S. Hernández Ruiz, G. Gómez Dacal. Fracasos escolares: estudio pedagógico, legal y económico. Madrid: Escuela Española.

Instituto de Estudios Sociológicos Bernard Krief. Didas-82: estudio sociológico sobre el fracaso escolar. Madrid: Didascalia.

Monográfico sobre fracaso escolar de la revista Perspectiva escolar.

MEC. La reforma de la Enseñanzas Medias: resultados de la consulta. Madrid: MEC.

Creación de la Sociedad Española de Psiquiatría y Psicoterapia del Niño y el Adolescente (SEPYPNA).

50 aniversario de la creación de la especialidad de Pedagogía en España («Los pedagogos no son responsables del fracaso escolar; éste viene de las deficiencias del sistema", declaran los organizadores). 